\title{
Redes neuronales aplicadas al control de riego usando instrumentación y análisis de imágenes para un micro- invernadero aplicado al cultivo de Albahaca
}

\author{
Martín Gerardo Vázquez Rueda, Marlen Ibarra Reyes, \\ Francisco Gerardo Flores García, Héctor Aurelio Moreno Casillas \\ Instituto Tecnológico de la Laguna, \\ Tecnológico Nacional de México Torreón Coahuila, \\ México \\ mart2vazquez@yahoo.com, marlen_mir@hotmail.com, \\ \{francisco.floresgarcia, honerom\}@gmail.com
}

\begin{abstract}
Resumen. El presente artículo muestra el desarrollo de un control con Inteligencia Artificial para un micro-invernadero utilizando redes neuronales artificiales multicapa de retro-propagacion. En el invernadero se analizan las plantas y se obtienen datos por medio de sensores, que permiten controlar y automatizar el riego. Mediante la interfaz se pueden observar los datos que monitorea el Sistema: la temperatura ambiente y la humedad relativa en el invernadero; la temperatura y humedad de cada una de las plantas, el tamaño de la planta, asi como el porcentaje sano y dañado de cada una de las plantas. El experimento fue realizado durante 44 días, probando las redes neuronales en un rango de humedad de 20 a $21 \%$ y una temperatura estable promedio de $30^{\circ} \mathrm{C}$. Con estas condiciones se encontró que las plantas de albahaca (Ocimum basilicum), se desarrollan favorablemente. El error para el control de Riego de la Red Neuronal Artificial (RNA) fue de solo 1.67\%.
\end{abstract}

Palabras clave: Control inteligente, micro invernadero, red neuronal artificial, temperatura, humedad, riego.

\section{Neural Networks Applied to Irrigation Control Using Instrumentation and Image Analysis for a Micro- Greenhouse Applied to the Cultivation of Basil}

\begin{abstract}
This article shows the development of a control using Artificial Intelligence for a micro-greenhouse using multilayer Backpropagation Artificial Neural Networks. In the micro-greenhouse the plants are analyzed and data obtained by sensors allowing to automate and control irrigation. Through the interface, the user can monitor the data of the system, the application shows: ambient temperature and relative moisture inside the greenhouse, temperature
\end{abstract}


and moisture for each plant, the size and percentage of healthy and damaged state of each plant. The experiment was performed for 44 days, testing the Artificial Neural Networks (ANN) within a moisture range of $20 \%$ to $21 \%$, and an average temperature of $30^{\circ} \mathrm{C}$. With these conditions it was found that basil plants (Ocimum basilicum) developed favorably. Error for the Irrigation Control of the ANN was only of $1.67 \%$.

Keywords: Intelligent control, micro greenhouse, artificial neural network, temperature, moisture, irrigation.

\section{Introducción}

\subsection{Agricultura de precisión}

El desarrollo de la agricultura ha derivado el uso de herramientas, actividades, materiales y estructuras que se emplean para la protección de los cultivos, conocido como la agricultura protegida. La agricultura protegida busca principalmente evitar las restricciones que el medio ambiente impone al desarrollo de las plantas cultivadas y se puede definir como "toda estructura cerrada, cubierta por materiales transparentes o semitransparentes, que permite obtener condiciones artificiales de microclima para el cultivo de plantas y/o flores, mediante la cual se tiene el propósito de alcanzar un adecuado crecimiento vegetal, aumentar rendimientos, mejorar la calidad y obtener excelentes cosechas" [1].

La agricultura protegida en México está en amplio crecimiento y desarrollo. De acuerdo con la SAGARPA, en el año 2000 solo existían 790 hectáreas de agricultura protegida en el país, con un crecimiento anual de 1,500 hectáreas para el 2015 el mismo organismo público un total de 23, 521 hectáreas lo que representa un crecimiento de 22, 461 hectáreas en solo 15 años. Según datos de la Asociación Mexicana de Horticultura Protegida (AMHPAC), hay un total de 25,814 instalaciones activas de agricultura protegida [2].

La comarca lagunera cuenta con una extensión territorial de 500,000 hectáreas y está situada en la parte suroeste del estado de Coahuila y noroeste del estado de Durango, la cual se caracteriza por pocas precipitaciones de lluvia, limitados recursos hídricos y su clima seco, caluroso en verano y frío en invierno, en donde las temperaturas siempre cambiantes y extremas llegan a alcanzar $\operatorname{los} 0^{\circ} \mathrm{C}$ a $45^{\circ} \mathrm{C}$, dependiendo de la estación del año, para combatir estos retos ambientales algunos productores han optado por la alternativa del uso de la agricultura protegida. La región lagunera del estado de Coahuila es conocida por actividades específicas de agricultura, cuenta con la mayor superficie de riego en el estado, sobresalen los cultivos de forrajes, melón, nuez, algodón y maíz: así como la producción de hortalizas, como tomate y chile en invernaderos y malla sombra [3].

Coahuila representa el $1.6 \%$ de hectáreas en agricultura protegida a nivel nacional, con el $0.8 \%$ de instalaciones activas. Siendo la comarca lagunera de Coahuila la región del estado con la mayor superficie que hace uso de la agricultura protegida, representando $81 \%$ de hectáreas cubiertas y el $37.14 \%$ de instalaciones en el estado, de 
las instalaciones que se encuentran en la comarca lagunera el invernadero es el tipo de agricultura protegida más utilizada con un $66.12 \%$ [1].

Con un crecimiento promedio anual del $12 \%$ la agricultura protegida mexicana cuenta con una infraestructura instalada cuyo valor es mayor a los 3,500 millones de dólares [2]. De las estructuras empleadas para proteger cultivos, los invernaderos permiten modificar y controlar de forma más eficiente los principales factores ambientales que intervienen en el crecimiento y desarrollo de las especies vegetales [4]. Los invernaderos y casa sombra se convierten en una de las economías más pujantes del sector primario. Siendo el invernadero el elemento cualitativamente más importante del sistema de producción en agricultura protegida, debido a que de él depende en gran medida la capacidad productiva [5].

Los sistemas que tienen alta Tecnología: en este nivel se incluyen instalaciones que cuentan con control climático automatizado (mayor independencia del clima externo), riegos, automatizados y de precisión, inyecciones de $\mathrm{CO} 2$, para ello cuentan con sensores y dispositivos que operan los sistemas de riego y ventilación, pantallas térmicas para el control de la iluminación y cultivo en sustratos [6].

El uso de invernaderos de alta tecnología se justifica mediante la corriente mundial de calidad en la que se vive. Los mercados son cada vez más exigentes en calidad, inocuidad, presentación y certificación del contenido [7].

Los invernaderos modernos son acondicionados con mecanismos y equipos necesarios para controlar temperatura, luminosidad, humedad ambiental y del sustrato, ventilación, aireación, aporte de $\mathrm{CO} 2$, riegos y fertilización.

El desarrollo de tecnologías aplicadas a invernaderos fomenta el aumento de calidad y conocimiento respecto a los cultivos. Si el monitoreo y análisis se realizan de forma automática crea una herramienta importante para incluir a las características de un invernadero de alta tecnología, que permitirá no solo cultivar para producción, sino que también se obtenga la capacidad de realizar análisis de cultivos, mejorando la toma de decisiones y generando una comprensión mayor del desarrollo de las plantas y cultivos.

\subsection{Inteligencia artificial}

La inteligencia artificial nace en una reunión celebrada en el verano de 1956 en Dartmouth (Estados Unidos) en la que participaron los que más tarde han sido los investigadores principales del área. Existen muchas definiciones de lo que es la inteligencia artificial. Sin embargo, todas ellas coinciden en la necesidad de validar el trabajo mediante programas [8].

Las redes neuronales son programas de la inteligencia artificial capaces de simular algunas de las funciones de aprendizaje del ser humano. Una red neuronal obtiene experiencia analizando automática y sistemáticamente los datos para determinar reglas de comportamiento; con base en ellas, puede realizar predicciones sobre nuevos casos. Estas técnicas se aplican a problemas de clasificación y series de tiempo e identifican conexiones con cosas que otras técnicas no pueden, porque utilizan relaciones lineales y no lineales [9].

Estas redes surgieron a partir de las ideas en la publicación de McCulloch y Pitts, donde se postula que las neuronas funcionan como dispositivos booleanos. Este 
postulado fue criticado como teoría biológica, pero permitió generar una neurona como un modelo lineal seguido de una función activación booleana.

Aquí, la función lineal representa la sinapsis (unión entre neuronas) y la agregación de la información, mientras que la función no lineal representa el procesamiento que hace la neurona. La función lineal se ve en la ecuación (1) [10]:

$$
r=f\left(\sum_{i=1}^{n} x_{i} w_{i}+b\right),
$$

donde $x_{i}$ son los datos de entrada, $w_{i}$ son los pesos sinápticos y $b$ es un factor de polarización, el resultado de $r$ es procesado de tal manera que a la salida de un valor de uno o cero, utilizando $f$ como función de transferencia harlim.

El proceso de aprendizaje consiste en hallar los pesos que codifican los conocimientos. Una regla de aprendizaje hace variar el valor de los pesos de una red hasta que estos adoptan un valor constante, cuando esto ocurre se dice que la red ya "ha aprendido" [11].

El perceptrón fue el primer modelo de red neuronal, el cual utiliza la neurona artificial de la Figura 1, además de que tenía su arquitectura en tres capas y un algoritmo de aprendizaje. Fué probado como un detector de caracteres ópticos, por lo que el campo de redes neuronales se inició como una forma de procesar imágenes [10].

El algoritmo backpropagation es el método de aprendizaje más frecuentemente utilizado en el entrenamiento de las redes. Este algoritmo de aprendizaje es una generalización de la regla de corrección de error de Widrow-Hoff. El error es la diferencia entre la salida que proporciona la RNA y la salida que se pretende obtener. Los diferentes pesos de las conexiones de las neuronas son corregidos mediante iteraciones que pretenden minimizar el error [12].

El presente trabajo se centra en el desarrollo de tecnologías aplicadas a invernaderos para el análisis de cultivos que permitan la obtención de conocimiento. Desarrollando una estación de trabajo automática que permitan el control de un microinvernadero de pruebas mediante una programación de inteligencia artificial que por medio de la obtención de variables realicen una toma de decisiones eficaces para optimizar el uso de agua para producir un cultivo de mejor calidad.

\section{Materiales y métodos}

\subsection{Micro-invernadero}

La estación de trabajo consta de una estructura con paredes de nylon transparente, contando con un sistema de circulación de aire. Emulando un invernadero en la cual se monitorea y controla el desarrollo de las plantas. Para esto se cuenta con diversos sistemas electrónicos, informáticos y estructurales, los cuales permiten procesamiento de imágenes, lecturas de sensores, controles para temperatura y riego. La estructura del invernadero está diseñada para contener 6 plantas. El sistema es de diseño propio.

Se cuenta con cinco sistemas diferentes: Sistema base, sistema de sensores, sistema riego, sistemas de riego, sistema de iluminación. Los sistemas están programados en el programa Labview para su interfaz y parte del control y cuentan con programas de Matlab y microcontroladores para los elementos matemáticos y electrónicos. 
Redes neuronales aplicadas al control de riego usando instrumentación y análisis de imágenes ...

El sistema base, es el que se encarga de la obtención de imágenes de las plantas mediante una cámara Microsoft LifeCam HD-6000, y el sistema ventilación del invernadero.

El sistema sensores engloba un sensor infrarrojo MXL90614 para medir la temperatura del ambiente dentro del invernadero y la temperatura objeto, es decir de cada una de las plantas, así como los seis sensores de humedad YL-69, cada uno correspondiente a una planta.

El sistema de riego es el encargado de suministrar determinadas cantidades de agua a las plantas. El módulo cuanta con tres válvulas solenoides $2 / 2$, tubería de agua, una bomba de agua, y un contenedor de agua, que proporciona el gasto adecuado acorde al tipo de planta [13].

\subsection{Metodología de experimento}

Para realizar estas pruebas se dividieron las plantas en 3 grupos quedando distribuidos como se muestra en la Tabla 1. La división de estos grupos se realizó debido a que se necesitaban obtener diferentes estados en las plantas y suministrando las diferentes cantidades de agua a cada sección, para lograr el objetivo de tener diferentes casos para el entrenamiento de la red neuronal artificial.

Tabla 1. Distribución de grupos para plantas de Albahaca.

\begin{tabular}{cl}
\hline Grupo & Plantas \\
\hline 1 & Planta 1 y 6 \\
\hline 2 & Planta 2 y 5 \\
\hline 3 & Planta 3 y 4 \\
\hline
\end{tabular}

Cada planta cuenta con un sensor de humedad en suelo YL-69, los cuales se insertaron de forma transversal en la maceta aproximadamente a la mitad de lo alto de la maceta. Una vez realizado el análisis, la lectura del sensor de humedad de agua en suelo arroja valores que van de 0 para tierra seca, es decir sin ninguna cantidad de agua, y hasta 25 que es la saturación del sensor y representa el $25 \%$ de humedad. Siendo el $100 \%$ de humedad el líquido directamente.

El sensor de temperatura infrarrojo MXL90614 es calibrado de fábrica para entregar temperaturas en rangos de -40 a $125{ }^{\circ} \mathrm{C}$ para temperaturas ambiente y -70 a $380{ }^{\circ} \mathrm{C}$ para temperaturas objeto. También cuenta con el sensor de humedad relativa HIH-4030 entrega valores de $0.8 \mathrm{~V}$ a $3.9 \mathrm{~V}$ escalados en porcentajes (0\% a 100\%) [14].

A partir del procesamiento de imagen se obtiene un porcentaje de follaje en buen estado y mal estado de la vista superior de la planta, además se proporciona la cantidad de área analizada de la planta solamente, discriminando las partes que no corresponden a la planta. La captura de la imagen es realizada por la cámara Microsoft LifeCam HD6000.

Para el procesamiento de imagen se tuvieron en cuenta las siguientes consideraciones [15]: El color de fondo alrededor de la planta a analizar deber ser blanco, esto para facilitar la detección del área que abarca la planta y discriminar el resto. La iluminación del invernadero debe estar encendida al momento de realizar el análisis de las plantas. 
Martín Gerardo Vázquez Rueda, Marlen Ibarra Reyes, Francisco Gerardo Flores García, et al.

Tabla 2. Horario de toma de muestras durante el análisis.

\begin{tabular}{cccccccc}
\hline M 1 & M 2 & M 3 & M 4 & M 5 & M 6 & M 7 & M 8 \\
\hline 00:30 & $03: 30$ & $06: 30$ & $09: 30$ & $12: 30$ & $15: 30$ & $18: 30$ & $21: 30$ \\
\hline
\end{tabular}

Tabla 3. Promedio de datos recopilados por día de la planta 1.

\begin{tabular}{cccccccc}
\hline Día & $\begin{array}{c}\text { Temperatura } \\
\text { Ambiente }\end{array}$ & $\begin{array}{c}\text { Humedad } \\
\text { Relativa }\end{array}$ & $\begin{array}{c}\text { Temperatura } \\
\text { Objeto }\end{array}$ & $\begin{array}{c}\text { Humedad } \\
\text { en Suelo }\end{array}$ & \% Bueno & \% Malo & Área Total \\
\hline 1 & 28.43 & 17.12 & 29 & 21.00 & 98.75 & 1.25 & 159872.00 \\
\hline 2 & 29.35 & 17.83 & 28.01 & 21.00 & 98.69 & 1.31 & 159213.00 \\
\hline 3 & 32.56 & 18.53 & 30.85 & 20.22 & 97.27 & 2.73 & 156719.00 \\
\hline
\end{tabular}

Tabla 4. Promedio de datos recopilados por día de la planta 6.

\begin{tabular}{cccccccc}
\hline Día & $\begin{array}{c}\text { Temperatura } \\
\text { Ambiente }\end{array}$ & $\begin{array}{c}\text { Humedad } \\
\text { Relativa }\end{array}$ & $\begin{array}{c}\text { Temperatura } \\
\text { Objeto }\end{array}$ & $\begin{array}{c}\text { Humedad } \\
\text { en Suelo }\end{array}$ & \% Bueno & \% Malo & Área Total \\
\hline 1 & 28.43 & 17.12 & 29.07 & 20.86 & 97.09 & 2.91 & 159878.00 \\
\hline 2 & 29.35 & 17.83 & 28.41 & 20.34 & 96.98 & 3.02 & 159226.00 \\
\hline 3 & 32.56 & 18.53 & 30.47 & 20.00 & 93.74 & 6.26 & 157718.00 \\
\hline
\end{tabular}

El algoritmo de procesamiento de imagen se centra en la detección de zonas amarillas en las hojas. El color amarillo en las hojas de una planta significa que hay un déficit de clorofila (clorosis) en la misma, se puede deber a varios motivos, los más comunes son: plagas que consuman la clorofila de la planta, falta de nutrientes, insuficiente exposición a la luz solar, falta de agua suficiente. Se debe tener cuidado que el campo de visión de la cámara y la captura realizada por esta contenga solamente a la planta a analizar.

Grupo de Estudio 1, Perteneciente a la sección 1 de riego. Sujeto de Estudio: Planta 1 y Planta 6. Las pruebas se realizaron del día 1 de Mayo del 2017 al día 14 de Junio del 2017, total 44 días.

Se realizaron 8 muestreos al día los cuales se seccionaron durante las 24 horas obteniendo así un muestro cada 3 horas. En la Tabla 2, se indica la hora a que se realizó el muestreo.

Total de muestras: Al finalizar se obtuvieron un total de 750 lecturas, siendo 350 correspondientes a la Planta 1 y 350 correspondientes a la Planta 6. Para este análisis se estableció un riego diario a las 14:30 horas y para este grupo de estudio se estableció $0 \mathrm{ml}$ de agua.

Los datos recopilados por ambas plantas son demasiados para ser presentados de forma completa, en la Tabla 3 y 4, se muestran algunos de los datos recopilados por día y para las seis regiones bajo prueba.

La figura 1, muestra las imágenes obtenidas para algunos casos en distintas plantas en diferentes etapas del proceso y bajo diferentes condiciones de humedad, las imagines son preprocesadas con algoritmos de tratamiento de imágenes, de las cuales se extraen el área total de la planta y el índice de PB porcentaje en buen estado. 

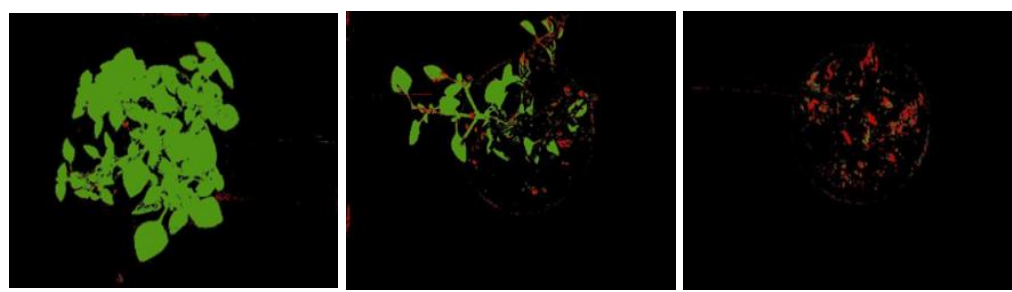

Fig. 1. Muestra de las imágenes originales en diferentes etapas del proceso.

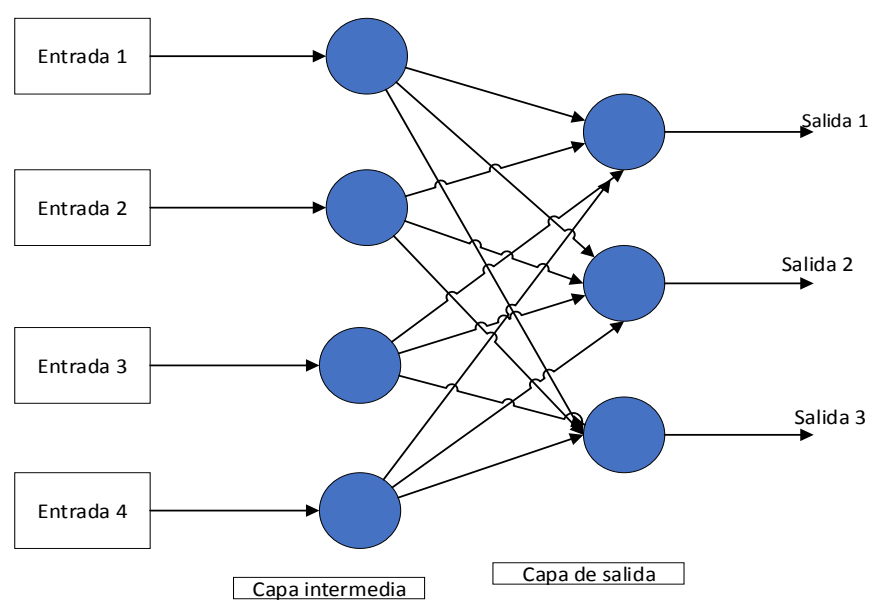

Fig. 2. Red Neuronal Artificial (RNA) para control de riego

Una red neuronal de retropropagación emplea el algoritmo del gradiente descendente, tal como la regla de aprendizaje Widrow-Hoff, en la cual, los pesos de la red se mueven a través de la parte negativa del gradiente de la función de desempeño. El término, retropropagación, se refiere a la forma en que el gradiente es calculado para redes multicapa no lineales, donde el error se calcula para ajustar los valores de los pesos propagándose hacia atrás [16]. Hay un gran número de variaciones, en el algoritmo básico, que están basadas en las técnicas de optimización estándar, tal como gradiente conjugado o el método de Newton [12].

Se empleó el ambiente de programación Matlab, para la generación, prueba y validación de las redes. Usando el algoritmo de Levenberg-Marquardt para su entrenamiento; función de aprendizaje por gradiente descendente con momento; como función de desempeño el cuadrado medio del error; una función de transferencia Hardlim para las capas ocultas y función de transferencia Hardlim para la capa de salida.

La red se diseñó con tres salidas, que pertenecen a tres niveles de riego, Bajo, Normal o Estable y Máximo o Excesivo. Con los datos obtenidos del experimento, donde las plantas tienen un desarrollo favorable en condiciones estables, se utilizaron para simular las redes neuronales del control de riego. La figura 2 muestra la arquitectura de la red. 


\section{Resultados y discusión}

Resultados de RNA de control de riego en sección 1. Tomando los datos de la humedad en suelo (HS) y el porcentaje de estado bueno (PB) de las plantas 1 y 6 como entradas para la red neuronal de la sección 1 del riego se procesaron los 20 casos y se obtuvo la siguiente respuesta de la red, representada en la Tabla 5.

Tabla 5. Respuesta de la RNA para riego de la sección 1 del micro-invernadero.

\begin{tabular}{ccccccc}
\hline Caso & $\begin{array}{c}\text { Entrada 1 } \\
\text { HS1 }\end{array}$ & $\begin{array}{c}\text { Entrada 2 } \\
\text { HS6 }\end{array}$ & $\begin{array}{c}\text { Entrada 3 } \\
\text { PB1 }\end{array}$ & $\begin{array}{c}\text { Entrada 4 } \\
\text { PB6 }\end{array}$ & $\begin{array}{c}\text { Salida } \\
\text { Deseada }\end{array}$ & $\begin{array}{c}\text { Salida de la } \\
\text { Red }\end{array}$ \\
\hline 1 & 21 & 21.5 & 98.75 & 98.1 & $\begin{array}{c}010= \\
\text { Humedad } \\
\text { Estable }\end{array}$ & $\begin{array}{c}010= \\
\text { Humedad } \\
\text { Estable }\end{array}$ \\
\hline 2 & 20 & 21.5 & 98.69 & 98.27 & $\begin{array}{c}\text { Humedad } \\
\text { Estable }\end{array}$ & $\begin{array}{c}\text { Humedad } \\
\text { Estable }\end{array}$ \\
\hline 3 & 21 & 21 & 98.27 & 97.91 & $\begin{array}{c}010= \\
\text { Humedad } \\
\text { Estable }\end{array}$ & $\begin{array}{c}010= \\
\text { Humedad } \\
\text { Estable }\end{array}$ \\
\hline 4 & 22 & 21.6 & 98.59 & 98.4 & $\begin{array}{c}001= \\
\text { Humedad } \\
\text { Excesiva }\end{array}$ & $\begin{array}{c}010= \\
\text { Humedad } \\
\text { Estable }\end{array}$ \\
\hline
\end{tabular}

Tabla 6. Respuesta de la RNA para riego de la sección 2 del micro-invernadero.

\begin{tabular}{ccccccc}
\hline Caso & $\begin{array}{c}\text { Entrada 1 } \\
\text { HS2 }\end{array}$ & $\begin{array}{c}\text { Entrada 2 } \\
\text { HS5 }\end{array}$ & $\begin{array}{c}\text { Entrada 3 } \\
\text { PB2 }\end{array}$ & $\begin{array}{c}\text { Entrada 4 } \\
\text { PB5 }\end{array}$ & $\begin{array}{c}\text { Salida } \\
\text { Deseada }\end{array}$ & $\begin{array}{c}\text { Salida de la } \\
\text { Red }\end{array}$ \\
\hline 1 & 21 & 20.7 & 98 & 97.87 & $\begin{array}{c}0 \\
\text { Humedad } \\
\text { Estable }\end{array}$ & $\begin{array}{c}\mathbf{0 ~ 1 ~ 0 ~ = ~} \\
\text { Humedad } \\
\text { Estable }\end{array}$ \\
\hline 2 & 21 & 20.7 & 98.51 & 97.77 & $\begin{array}{c}010 \\
\text { Humedad } \\
\text { Estable }\end{array}$ & $\begin{array}{c}\mathbf{0 ~ 1 ~ 0 ~ = ~} \\
\text { Humedad } \\
\text { Estable }\end{array}$ \\
\hline 3 & 21 & 20.74 & 97.99 & 97.77 & $\begin{array}{c}010 \\
\text { Humedad } \\
\text { Estable }\end{array}$ & $\begin{array}{c}\text { 0 1 0 = } \\
\text { Humedad } \\
\text { Estable }\end{array}$ \\
\hline
\end{tabular}

De la tabla 5 con todos los datos extraídos en la sección de riego 1 del microinvernadero la red da un $95 \%$ de aciertos en su salida, $5 \%$ de error.

Resultados de RNA de control de Riego en sección 2. Tomando los datos de la humedad en suelo y el porcentaje de estado bueno de las plantas 2 y 5 como entradas para la red neuronal de la sección 2 del Riego se procesaron los 20 casos y se obtuvo la siguiente respuesta de la red, representada en la Tabla 6.

De la tabla 6 se muestra que en la sección de riego 2 del micro-invernadero la red fue $100 \%$ asertiva en su salida.

Resultados de RNA de control de riego en sección 3. Tomando los datos de la humedad en suelo y el porcentaje de estado bueno de las plantas 3 y 4 como entradas para la red neuronal de la sección 3 del Riego se procesaron los 20 casos y se obtuvo la siguiente respuesta de la red, representada en la Tabla 7. 
Redes neuronales aplicadas al control de riego usando instrumentación y análisis de imágenes ...

Tabla 7. Respuesta de la RNA para riego de la sección 3 del micro-invernadero.

\begin{tabular}{ccccccc}
\hline Caso & $\begin{array}{c}\text { Entrada 1 } \\
\text { HS3 }\end{array}$ & $\begin{array}{c}\text { Entrada 2 } \\
\text { HS4 }\end{array}$ & $\begin{array}{c}\text { Entrada 3 } \\
\text { PB3 }\end{array}$ & $\begin{array}{c}\text { Entrada 4 } \\
\text { PB4 }\end{array}$ & $\begin{array}{c}\text { Salida } \\
\text { Deseada }\end{array}$ & $\begin{array}{c}\text { Salida de la } \\
\text { Red }\end{array}$ \\
\hline 1 & 21.3 & 21.2 & 98.28 & 97.6 & $\begin{array}{c}010= \\
\text { Humedad } \\
\text { Estable }\end{array}$ & $\begin{array}{c}\text { 0 1 0 }= \\
\text { Humedad } \\
\text { Estable }\end{array}$ \\
\hline 2 & 21 & 21 & 98.1 & 97.78 & $\begin{array}{c}010= \\
\text { Humedad } \\
\text { Estable }\end{array}$ & $\begin{array}{c}\text { 0 1 0 = } \\
\text { Humedad } \\
\text { Estable }\end{array}$ \\
\hline 3 & 21 & 21.2 & 98.4 & 97.87 & $\begin{array}{c}010= \\
\text { Humedad } \\
\text { Estable }\end{array}$ & $\begin{array}{c}\text { 0 1 0 = } \\
\text { Humedad } \\
\text { Estable }\end{array}$ \\
\hline
\end{tabular}

De la tabla 7 se muestra que en la sección de riego 3 del invernadero la red fue $100 \%$ asertiva en su salida.

Tomando en consideración las tres secciones, se puede concluir que la RNA del control de Riego tiene un margen de error del $1.67 \%$. La cantidad de agua requerida por las plantas de Albaca, así como las condiciones necesarias para su crecimiento [13].

\section{Conclusiones y trabajo futuro}

Se cumplio con el objetivo principal de diseñar e implementar un control inteligente a la estación de trabajo del micro-invernadero, el cual permite mantener un riego eficiente para mejorar el desarrollo de los cultivos, sin tener que estar al pendiente las $24 \mathrm{hrs}$ del invernadero para realizar los cambios manualmente. La implementación del control inteligente permite: Un control del sistema de riego en el cual según el estado de humedad de la planta es la cantidad de agua que suministra, si la planta se encuentra normal sigue con la misma cantidad $(60 \mathrm{ml})$ si la planta esta deshidratada aumenta la cantidad de agua hasta que la planta se regula a su estado estable y si la planta se encuentra sobre hidratada disminuye la cantidad de agua suministrada hasta que la planta vuelva a estar en condiciones estables [13].

Visualizar las últimas imágenes de las seis plantas capturadas por la cámara y las seis imágenes después del procesamiento de imagen, permitiendo conocer el estado actual de las plantas de forma visual.

Permite tener un historial de análisis de cada planta a través de reportes los cuales son guardados en tablas de Excel. Con los reportes se puede observar las lecturas de los sensores como lo son la temperatura ambiente, temperatura directa, humedad relativa y humedad de agua en suelo, además de los resultados arrojados por el procesamiento de imagen, las fechas y horas de análisis.

Como trabajos a Futuro se tiene en cuenta lo siguiente: Implementar un sistema de calefacción. Añadir al sistema de sensado de macronutrientes esenciales. Que integrándolo en un sistema con inteligencia artificial pueden mejorar el proceso de producción de plantas, generando diferentes estrategias de control con inteligencia artificial incluyendo otras variables y procesos. 
Agradecimientos. Se agradece al soporte brindado por el CONACYT, al Tecnológico Nacional de México, al Instituto Tecnológico de la Laguna, por el apoyo brindado para el desarrollo de este proyecto.

\section{Referencias}

1. Santos-Bielinski, M., Obregón-Henner, A., Salamé-Teresa P.: Producción de Hortizales en Ambientes Protegidos: Estructuras para la Agricultura Protegida, Publicación del Departamento de Horticultural Sciences, UF/IFAS Estension, University of Florida, 2(5), pag. 99-110 (2016)

2. AMHPAC: Asociación Mexicana de Horticultura Protegida Agricultura Protegida en México. http://www.amhpac.org/es/index.php/homepage/agricultura-protegida-enmexico (2015)

3. Secretaria de Desarrollo Rural del Gobierno de Estado de Coahuila de Zaragoza.: Programa Estatal de Desarrollo Rural 2011-2017. http://coahuila.gob.mx/archivos/pdf/Publicaciones /DESARROLLO\%20RURAL.pdf (2017)

4. Juárez-López, P., Bugarín-Montoya, R., Castro-Brindis, R., Sánchez-Monteón, A.L., CruzCrespo, E., Juárez-Rosete, C.R., Alejo-Santiago, G., Balois-Morales, R.: Estructuras utilizadas en la agricultura protegida. Revista Fuente, Año 3, 8, pp. 21-27 (2011)

5. Ortega-Martínez, L.D., Ocampo-Mendoza, J., Sandoval-Castro, E., Martínez-Valenzuela, C., Huerta-De La Peña, A., Jaramillo-Villanueva, J.L.: Caracterización y funcionalidad de invernaderos en Chignahuapan, Puebla. Colegio de Postgraduados Campus Puebla, Revista Bio Ciencias, pp. 261-270 (2014)

6. SAGARPA: Servicio de Información Agroalimentaria y Pesquera. Agricultura Protegida. http://www.gob.mx/siap/documentos/agricultura-protegida (2017)

7. Pacheco, A.J: Fundamentos técnicos para el diseño y construcción de invernaderos. (AGRO), 51, pp. 12-19 (2008)

8. Torra, V.: La Inteligencia Artificial. Lychnos 7, pp. 14-19 (2011)

9. García-Fernández, L.A.: Usos y aplicaciones de la inteligencia artificial. La ciencia y el hombre, 17(3), pp. 29-32 (2004)

10. Ramírez, Q., Juan, A., Chacón, M., Mario, I.: Redes neuronales artificiales para el procesamiento de imágenes, una revisión de la última década. (RIEE\&C), Revista de Ingeniería Eléctrica, Electrónica y Computación, 9(1), pp. 7-16 (2011)

11. Sotolongo, G., Guzmán, M.V.: Aplicaciones de las redes neuronales. El caso de la bibliometría, Ciencias de la Información, 32(1), pp. 27-34 (2001)

12. Martín del Brío, B., Sanz-Molina, A.: Redes Neuronales y Sistemas Difusos. Editorial Rama (2006)

13. Martinez-Beranal, L.F.: Determinación del requerimiento hídrico de la albahaca (Ocimun basilicum) y comparación de dos sistemas de microirrigación (microaspersión y goteo) en condiciones de clima frio, bajo invernadero https://www.researchgate.net/ publication/3060 91339_Determinacion_del_requerimiento_hidrico_de_la_albahaca_Ocimun_basilicum_y_ comparacion_de_dos_sistemas_de_microirrigacion_microaspersion_y_goteo_en_condicio nes_de_clima_frio_bajo_invernadero (2018)

14. Galicia-Reyes, J.I.: Aplicación para control vía remota, integración de sensores y sistema de riego a invernadero de pruebas automático para el monitoreo de plantas. Tesis de maestría, Instituto Tecnológico de la Laguna (2015)

15. Avilés de León, Y.: Estación de Trabajo Automática para el Monitoreo de Plantas, Tesis de maestría, Instituto Tecnológico de la laguna (2014) 
Redes neuronales aplicadas al control de riego usando instrumentación y análisis de imágenes ...

16. Valencia Reyes Marco Antonio, Yáñez Márquez Cornelio, Sánchez Fernández Luis Pastor.: Algoritmo Backpropagation para Redes Neuronales: conceptos y aplicaciones, IPN CIC 125(1), 1-14, 2006. 